- U xâm lấn trung bì có số nhân chia > $6 / \mathrm{mm} 2$ cao nhất 38,3\%, thấp nhất nhân chia < $1 / \mathrm{mm} 2$ là $28,4 \%$, lympho xâm nhập u dầy đă̆c $30,5 \%$, không có lympho bào xâm nhập 36,2\%. Chưa di căn hạch là 45,9\%, giai doạn 2 là $45,9 \%$, giai đoạn 3 là $54,1 \%$.

\section{Một số yếu tố tiên lượng}

- Tỷ lệ sống thêm 5 năm toàn bộ $42,4 \%$.

- Vị trí khối u, típ mô bệnh học, độ dầy u, mức độ Clark, giai đoạn phát triển, nhân vệ tinh, loét u nguyên phát, xâm nhập mạch, tỷ lệ nhân chia, lympho xâm nhập u, số hạch khu vực di căn, giai đoạn bệnh là những yếu tố tiên lượng quan trọng ảnh hưởng đến tỷ lệ sống thêm.

\section{TÀI LIÊU THAM KHẢO}

1. Albino A.P, Reed J.A., McNutt N.S et al. (1997). Molecular Biology of Cutaneous Melanoma, Principles and practice of Oncology. Lippincott Raven, 2, 46.
2. Marc Hurlbert (2020). 2020 Melanoma mortality rates decreasing despite ongoing increase in incidence. Melanoma research Alliance.

3. Phạm Hoàng Anh và cộng sự (1993), Ung thư Hà Nội 1991- 1992, y học Việt Nam; chuyên đề ung thư, tập 173, số 7, 14-21.

4. Balch CM, Joong SJ, et al. (2001). Prognostic factors analysis of 17.600 melanoma patients: validation of the American Joint Committee on Cancer melanoma staging system. J Clin Oncol,19(16), 3622-34.

5. Garbe C., Butner P., Bertz J. et al. (1995) Primary cutaneous melanoma, identification of prognostic group and estimation of individual prognostic for 6599 patients. Cancer, 75, 2484-91.

6. Clark WH Jr Elder DE, et al. (1989). Model predicting survival in stage I melanoma based on tumor progression. JNCI, 81, $1893-1904$.

7. Barnhill RL, Fine JA, Roush GC, Berwick M. (1996). Predicting five-year outcome for patients with cutaneous melanoma in a population-based study. Cancer, 78,427-432.

\title{
SỰ HÀI LÒNG VỚI CÔNG VIỆC CỦA Đİ̂̀U DƯỡNG VÀ MộT SỐ YẾU TỐ ẢNH HƯỞNG TẠI BỆNH VIỆN ĐA KHOA TRUNG TÂM TIỀN GIANG NĂM 2019
}

\section{TÓM TẮT}

Nghiên cứu "Sứ hài lòng với công viêc của điều dưỡng và một số yễu tố ảnh hưởng tại Bệnh viện Đa khoa Trung tâm Tiên Giang năm 2019" được thực hiện từ tháng 3/2019 đến tháng $9 / 2019$, bằng phương pháp nghiên cứu mô tả cắt ngang kết hợp phân tích định lượng và định tính, phát vẩn 257 điều dưỡng đang làm việc tại các khoa phòng của Bệnh viện Đa khoa Trung tâm Tiền Giang, đồng thời tiến hành phỏng vấn sâu một số lãnh đạo Bệnh viện và các khoa phòngvới 2 mục tiêu: (1) Mố tả sự hài lòng với công việc của điều dưỡng tại Bệnh viện Đa khoa Trung tâm Tiền Giang năm 2019; (2) Phân tích một số yếu tố ảnh hưởng đển sự hài lòng với công việc của điêu dưỡng tại Bệnh viện Đa khoa Trung tâm Tiên Giang năm 2019. Kết quả nghiên cứu cho thấy: điểm trung bình hài lòng về môi trường làm việc là $3,35 / 5$ (thang điểm 5) chiếm tỉ lệ 67\%; điểm trung bình hài lòng chung với lãnh đao trực tiếp, đồng nghiệp là 3,71 (thang điểm 5), chiếm tî lệ 74,2\%; điểm trung bìnhhài lòng chung với quy chế nội bộ, tiền lương, phúc lợi là 3,48 (thang điểm 5), chiếm tî lệ 69,6\%. Điểm trung bìnhhài lòng chung với công việc, cơ hội học tập và thăng tiến

\footnotetext{
${ }^{1}$ Bệnh viện $Đ K T T$ Tiền Giang

2 Trường $Đ H Y$ Dước, $Đ H$ Quốc gia $H N$

Chịu trách nhiệm chính: Lê Thị Hằng

Email: hang.vnu65@gmail.com

Ngày nhận bài: 14/8/2021

Ngày phản biên khoa hoc: 11/9/2021

Ngày duyệt bài: 29/9/2021
}

\section{Nguyễn Ngọc Bảo Châu ${ }^{1}$, Lê Thị Hằng ${ }^{2}$ và $\mathrm{CS}$}

là 3,55 (thang điểm 5), chiếm tỉ lệ $71 \%$. Một số yếu tố ảnh hưởng tiêu cực đến sư hài lòng với công việc của điều dưỡng như: cơ sở vật chất cũ xuống cấp, trang bị bảo hộ lao động như khẩu trang còn thiếu, lương còn thấp, áp lực công việc lớn nhưng chưa được quan tâm của lãnh đạao khoa phòng, một số bệnh nhân thiếu tôn trọng và hợp tác với điều dưỡng... Nghiên cứu chỉ ra, lãnh đạo cần quan tâm và đối xử bình đẳng với điều dưỡng, tạo nguồn kinh phí chi trả tiền lương và phụ cấp tương xứng với cống hiến của điều dưỡng do bệnh viện tự chi hoàn toàn và phân công công việc phù hợp với vị trí của từng điêuu dưỡng. Đối với đội ngũ điều dưỡng cần rèn luyện, trau dồi, học tập nâng cao trình độ chuyên môn, nghiệp vụ, cập nhật kiến thức mới và thực hành tốt y đức.

Tư khóa: Sự hài lòng, điều dương.

\section{SUMMARY}

SATISFACTION WITH THE JOB OF NURSING AND SOME INFLUENCING FACTORS AT TIEN GIANG CENTRAL GENERAL HOSPITAL IN 2019

Research "Satisfaction with the job of nursing and some influencing factors at Tien Giang Central General Hospital in 2019" was conducted from March 2019 to September 2019 with the goal: 1) Describe the satisfaction with the job of nursing in Central Hospital in Tien Giang in 2019. 2)Analyze some factors affecting the job satisfaction of nursing at Central General Hospital Tien Giang Center in 2019. The research method is cross-sectional description combining quantitative and qualitative analysis. The 
study author interviewed 257 nurses who were working in the departments of Tien Giang Central General Hospital, and also conducted in-depth interviews with some hospital leaders and departments. The results showed that the average satisfaction point for the working environment was $3.35 / 5$ (5 point scale), accounting for $67 \%$; The average overall satisfaction score with direct leaders and colleagues is 3.71 (on a 5-point scale), accounting for $74.2 \%$; The average point of overall satisfaction with internal regulations, salary and benefits is 3.48 (5 point scale), accounting for $69.6 \%$. The average overall satisfaction with job, learning opportunities and advancement is 3.55 ( 5 point scale), accounting for $71 \%$. Some factors that affect job satisfaction with nursing include: Job placement, health policy, psychological atmosphere, office culture.The study recommends that the hospital managers need to pay attention and treat nurses equally, generate completely self-funded sources to pay nurses compensation and benefits in alignment with their dedication and efforts, and assign jobs suitable to the position of each nurse. Nursing team needs to practice well the code of conduct, maintain and promote good discipline, discipline, responsibility and cultural lifestyle in the workplace, always dedicated, loving and caring. take care of patients comprehensively and become health workers good at medicine, fluent in medicine and good ethical practice.

Keyword: Satisfaction, nursing.

\section{I. ĐẶT VẤN ĐỀ}

Bệnh viện Đa khoa Trung tâm Tiên Giang là Bệnh viện Đa khoa tuyến tỉnh hạng I với quy mô 780 giường bệnh và 901 cán bộ, viên chức. Là cơ sở khám chữa bệnh cho nhân dân trong tỉnh và vùng ven các tỉnh lân cận như Long An, Bến Tre, Vînh Long, Đồng Tháp [2]. Dịch vụ chăm sóc của điều dưỡng trực tiếp tác động vào chất lượng điêu trị, giảm tỷ lệ mắc bệnh, giảm biến chứng và tử vong cho người bệnh. Tuy nhiên, đội ngũ điều dưỡng vẫn còn một số bất cập như: chưa được đâu tư thoả đáng cả về số lượng và chất lượng, mức thu nhập của người điều dưỡng chưa cao, chưa nhìn nhận đúng vai trò của người điều dưỡng. Để người điều dưỡng có thể phát huy hết khả năng, năng lực, thực hiện đúng chức năng và nhiệm vụ của mình thì sự hài lòng của điều dưỡng là hết sức cần thiết trong công việc.

Vì vậy, chúng tôi tiến hành nghiên cứu đề tài: "Sự hài lòng với công việc của điều dưỡng và một số yếu tố ảnh hưởng tại Bệnh viện Đa khoa Trung tâm Tiền Giang năm 2019", với mục tiêu sau:

- Mô tả sự hài lòng với công việc của điều dưỡng tại Bệnh viện Đa khoa Trung tâm Tiền Giang năm 2019.

- Phân tích một số yếu tố ảnh hưởng đến sự hài lòng với công việc của điều dướng tại Bệnh viện Đa khoa Trung tâm Tiền Giang năm 2019.

\section{II. ĐỐI TƯỢNG VÀ PHƯƠNG PHÁP NGHIÊN CỨU}

\section{1. Đối tượng nghiên cứu}

2.1.1. Đối tượng nghiên cứu định lượng: Điều dưỡng tại các Khoa, Phòng thuộc Bệnh viện Đa khoa Trung tâm Tiền Giang năm 2019.

Số liệu thứ cấp: Các báo cáo tổng kết hoạt động nắm của Bệnh viện Đa khoa Trung tâm Tiền Giang từ năm 2015, 2016, 2017, 2018, 2019.

2.1.2. Đối tượng nghiên cứu định tính. Điều dưỡng viên tại các khoa, phòng và Lãnh đạo bệnh viện, lãnh đạo Phòng, Khoa.

2.2. Thời gian và địa điểm nghiên cứu . Nghiên cứu được tiến hành từ tháng 3/2019 đến tháng 9/2019 tại Bệnh viện Đa khoa Trung tâm Tiền Giang. Địa chỉ: Số 02 Hùng Vương, Phường 1, TP Mỹ Tho, Tiền Giang.

2.3. Thiết kế nghiên cứu: Nghiên cứu mô tả cắt ngang kết hợp phân tích định lượng và định tính.

\subsection{Cỡ mẫu}

2.4.1. Cỡ mẫu cho nghiên cứu định lượng:

- Cõ̃ mẫu được tính theo công thức:

$$
\mathrm{n}=\frac{\mathrm{Z}^{2}\left(1-\mathrm{a}^{2}\right) * \mathrm{p}^{*}(1-\mathrm{p})}{\mathrm{d}^{2}}
$$

Với ước tính tỷ lệ hài lòng với công việc của điều dưỡng $p=70,8 \%$ [6]

Cỡ mẫu tính được $n=200$.

- Thực tế cõ mẫu nghiên cứu: $\mathrm{n}=257$

Chọn mẫu chủ đích, gồm 257 điều dưỡng làm việc từ 6 tháng trở lên tại các Khoa, Phòng thuộc Bv Đa khoa Trung tâm Tiền Giang năm 2019.

2.4.2. Cỡ mấu cho nghiên cứu định tính. Chọn mẫu có chủ đích, cụ thể: Phỏng vấn sâu Giám đốc, Trưởng phòng Tổ chức Hành chính, Trưởng phòng Điều dưỡng, điều dưỡng hành chính, điều dưỡng lâm sàng, điêu dưỡng cận lâm sàng.

2.5. Phân tích số liệu. Số liệu được làm sạch, nhập vào máy tính với phần mềm Epi Data 3.1 và được xử lý bằng phần mềm SPSS (Statistical Package for Social Sciences) phiên bản 22.0 cho các thông tin mô tả và phân tích thống kê.

Thang điểm Likert (1): Rất không hài lòng, 2: Không hài lòng, 03: Bình thường, 04: Hài lòng, 05: Rất hài lòng) được mã hóa thành 2 nhóm: nhóm chưa hài lòng từ $1-3$ điểm và nhóm hài lòng từ $4-5$ điểm, đối với từng tiểu mục.

Các số liệu định tính được xử lý theo theo từng chủ đề.

2.6. Vấn đề đạo đức trong nghiên cứu : Nghiên cứu được Hội đồng Đạo đức - Trường Đại học Y tế Cổng cộng xem xét và quyết định thông qua. 
III. KẾT QUẢ NGHIÊN CỨU VÀ BÀN LUÂN

Tiến hành khảo sát trên 257 điều dưỡng về sự hài lòng đối với công việc tại các khoa, phòng Bệnh viện Đa khoa Trung tâm Tiền Giang năm 2019, kết quả như sau:

3.1. Đặc điểm chung của đối tượng nghiên cứu

3.1.1. Đặc điểm về giới, nhóm tuổi, tuổi nghề, vị trí việc làm, tần suât ca trực của đôi tương nghiên cứu

Bảng 3.1. Phân bố đối tượng nghiên cứu theo khoa/phòng

\begin{tabular}{|c|c|c|}
\hline $\begin{array}{c}\text { Vị trí công tác theo } \\
\text { khoa/phòng }\end{array}$ & $\begin{array}{c}\text { Số lượng } \\
\text { (n) }\end{array}$ & $\begin{array}{c}\text { Tỷ lệ } \\
\text { (\%) }\end{array}$ \\
\hline Hành chính & 04 & 1,56 \\
\hline Khoa nội & 103 & 40,08 \\
\hline Khoa nhi & 16 & 6,23 \\
\hline Khoa ngoại & 47 & 18,29 \\
\hline Khoa Ung bướu & 07 & 2,72 \\
\hline Phâ̂u thuật - gây mê hồi sức & 13 & 5,06 \\
\hline Khoa khám bệnh & 22 & 8,56 \\
\hline Khoa Hồi sức cấp cứu & 36 & 14,01 \\
\hline Chuyên khoa lẻ (TMH, RHM) & 09 & 3,50 \\
\hline
\end{tabular}

Trong 257 điều dưỡng tham gia nghiên cứu, điều dưỡng khoa Nội chiếm tỷ lệ cao nhất tới $40,08 \%$, tiếp theo là khoa Ngoại chiếm tỷ lệ 18 , $29 \%$.

Bảng 3.2. Phân bố đôi tượng nghiên cứu theo giới, nhóm tuổi và tuổi nghề

\begin{tabular}{|c|c|c|}
\hline Giới tính & Số lượng (n) & Tỷ lệ (\%) \\
\hline Nam & 39 & 15,18 \\
\hline Nữ & 218 & 84,82 \\
\hline \multicolumn{3}{|c|}{ Nhóm tuối } \\
\hline Từ 20 - 30 tuối & 130 \\
\hline Từ 31 - 45 tuối & 93 & 50,58 \\
\hline Từ 46-60 tuối & 34 & 36,19 \\
\hline \multicolumn{3}{|c|}{ Tuối nghề } \\
\hline Dưới 1 năm & 13 \\
\hline Từ 1 - 15 năm & 190 & 5,23 \\
\hline Từ 16 - 30 năm & 44 & 13,93 \\
\hline Từ 31 - 40 năm & 10 & 3,89 \\
\hline
\end{tabular}

Trong 257 điều dưỡng tham gia nghiên cứu, điều dưỡng nữ chiếm đa số với tỷ lệ $84,82 \%$. Nhóm tuổi tữ 20-30 tuổi, chiếm tỷ lệ cao tới $50,58 \%$ và cũng tương đồng với nhóm tuổi nghề $<15$ năm chiếm đa số $73,93 \%$.

Bảng 3.3. Đặc điểm về kiêm nhiệm công việc và vị trí việc làm của điều dướng

\begin{tabular}{|c|c|c|}
\hline Kiêm nhiệm công việc & $\begin{array}{c}\text { Số lượng } \\
\text { (n) }\end{array}$ & $\begin{array}{c}\text { Tỷ lệ } \\
\text { (\%) }\end{array}$ \\
\hline Không kiêm nhiệm & 153 & 59,53 \\
\hline Kiêm nhiệm 2 công việc & 73 & 28,40 \\
\hline Vị trí việc làm & \multicolumn{2}{|c|}{} \\
\hline Điều dưỡng trưởng khoa & 19 & 7,39 \\
\hline Điều dưỡng hành chính & 37 & 14,40 \\
\hline Điều dương chăm sóc & 201 & 78,21 \\
\hline $\begin{array}{c}\text { Kiêm nhiệm từ } 3 \text { công } \\
\text { việc trở lên }\end{array}$ & 31 & 12,07 \\
\hline
\end{tabular}

Điều dưỡng kiêm nhiệm từ 2 công việc chiếm $28,40 \%$, kiêm nhiệm từ 3 công việc trở lên chiếm $12,07 \%$. Điều dưỡng chăm sóc chiếm đa phần $78,21 \%$.

Bảng 3.4. Tần suất ca trực trong tháng của điều dưỡng tham gia nghiên cứu

\begin{tabular}{|c|c|c|}
\hline $\begin{array}{c}\text { Số lần ca trực } \\
\text { trong tháng }\end{array}$ & $\begin{array}{c}\text { Số } \\
\text { lượng(n) }\end{array}$ & Tỷ lệ (\%) \\
\hline Không trực & 35 & 13,62 \\
\hline 01 lần & 05 & 1,95 \\
\hline 02 lần & 03 & 1,27 \\
\hline 03 lần & 03 & 1,27 \\
\hline 04 lần & 20 & 7,78 \\
\hline 05 lần & 76 & 29,56 \\
\hline 06 lần & 50 & 19,46 \\
\hline 07 lần & 14 & 5,45 \\
\hline 08 lần & 47 & 18,29 \\
\hline 09 lần & 1 & 0,39 \\
\hline 10 lần & 3 & 1,27 \\
\hline
\end{tabular}

Điều dưỡng trực 5-6 lần/tháng chiếm đa sô trong tổng số tham gia nghiên cứu.

\subsection{Sự hài lòng của điều dưỡng}

3.2.1. Sự hài lòng về môi trường làm việc

Bảng 3.5. Điểm trung bình hài lòng với môi trường làm việc

\begin{tabular}{|c|c|c|c|c|}
\hline $\begin{array}{c}\text { Mã } \\
\text { câu } \\
\text { hỏi }\end{array}$ & Nội dung câu hỏi & $\begin{array}{c}\text { Điêu dưỡng } \\
\text { hài lòng }\end{array}$ & $\begin{array}{c}\text { Điểm } \\
\text { trung } \\
\text { bình }\end{array}$ & $\begin{array}{c}\text { Độ leêch } \\
\text { chuẩn }\end{array}$ \\
\hline A1 & Phòng làm việc của anh/chị sạch sẽ, thoáng mát. & $121(47,08 \%)$ & 3,47 & 0,83 \\
\hline A2 & Trang thiết bị văn phòng, bàn ghế làm việc đây đủ. & $120(46,69 \%)$ & 3,40 & 0,80 \\
\hline A3 & Các thiết bị cũ, lạc hậu được thay thế kịp thời. & $94(36,58 \%)$ & 3,21 & 0,80 \\
\hline A4 & Có bố trí phòng tực cho điêu dưỡng. & $149(57,98 \%)$ & 3,54 & 0,77 \\
\hline A5 & Phân chia thời gian trực hợp lý. & $154(59,92 \%)$ & 3,60 & 0,67 \\
\hline A 6 & Phân chia thời gian làm việc ngoài giờ hành chính hợp lý. & $134(52,14 \%)$ & 3,52 & 0,67 \\
\hline A7 & Các trang bị bảo hộ cho điều dưỡng (quần áo, khẩu trang, & $111(43,19 \%)$ & 3,30 & 0,88 \\
\hline
\end{tabular}




\begin{tabular}{|c|c|c|c|c|}
\hline & găng tay...) đây đủ. & & & \\
\hline A8 & Không bị cũ, nhàu nát, không bị hạn chế sử dụng. & $116(45,14 \%)$ & 3,41 & 0,76 \\
\hline A9 & $\begin{array}{l}\text { Môi trường học tập tạo điều kiện cho điều dưỡng cập nhật } \\
\text { kiến thức, nâng cao trình độ: thư viện, phòng đọc sách, } \\
\text { tra cứu thông tin, truy cập internet... }\end{array}$ & $104(40,47 \%)$ & 3,23 & 0,95 \\
\hline A10 & Môi trường làm việc bảo đảm an toàn cho điều dưỡng. & $92(35,80 \%)$ & 3,23 & 0,79 \\
\hline A11 & Bệnh viện bảo đảm an ninh, trật tự cho điều dưỡng làm việc. & $88(34,24 \%)$ & 3,11 & 0,90 \\
\hline A12 & $\begin{array}{l}\text { Người bệnh và người nhà có thái độ tôn trong, hợp tác với } \\
\text { điều dưỡng trong quá trình điêu trị. }\end{array}$ & $82(31,91 \%)$ & 3,19 & 0,68 \\
\hline \multicolumn{3}{|c|}{ Điểm trung bình hài lòng chung với môi trường làm việc } & \multicolumn{2}{|c|}{$3,35 \pm 0,55$} \\
\hline
\end{tabular}

Bảng 3.5 cho thấy, tiểu mục $A 12$, điều dưỡng hài lòng thấp chỉ đạt $31,91 \%$. Điểm trung bình hài lòng về môi trường làm việc là $3,35 / 5$ điểm chiếm tỉ lệ $67 \%$. Kết quả này phù hợp với nghiên cứu của phòng Quản lý chất lượng Bệnh viện điểm trung bình năm 2018 là 3,73 điểm [2] và 06 tháng đầu năm 2019 là 3,65 điểm [3]. Nghiên cứu của Lê Trí Khải và cộng sự cho thấy điểm trung bình hài lòng về cơ sở vật chất, trang thiết bị của NVYT là 3,61 điểm [4], tương đồng với kết quả của chúng tôi.

\subsubsection{Sự hài lòng về lãnh đạo trực tiếp, đồng nghiệp}

Bảng 3.6. Điểm trung bình hài lòng với lãnh đạo trực tiểp, đồng nghiệp

\begin{tabular}{|c|c|c|c|c|}
\hline $\begin{array}{l}\text { Mã câ } \\
\text { hỏi }\end{array}$ & Nội dung câu hỏi & $\begin{array}{c}\text { Đî̀u dưỡng } \\
\text { hài lòng }\end{array}$ & $\begin{array}{c}\text { Điểm trung } \\
\text { bình }\end{array}$ & $\begin{array}{l}\text { Độ lệch } \\
\text { chuẩn }\end{array}$ \\
\hline B1 & $\begin{array}{c}\text { Lãnh đạo có năng lực xử lý, điều hành, } \\
\text { giải quyết công việc hiệu quả. }\end{array}$ & $\begin{array}{c}155 \\
(60,31 \%)\end{array}$ & 3,64 & 0,67 \\
\hline B2 & $\begin{array}{l}\text { Lãnh đạo phân công công việc phù hợp với chuyên } \\
\text { môn đào tạo của điều dưỡng. }\end{array}$ & $\begin{array}{c}167 \\
(64,98 \%) \\
\end{array}$ & 3,70 & 0,59 \\
\hline B3 & $\begin{array}{l}\text { Lãnh đạo quan tâm, tôn trọng, đối xử bình đằng với } \\
\text { các điều dưỡng. }\end{array}$ & $\begin{array}{c}147 \\
(57,20 \%)\end{array}$ & 3,59 & 0,70 \\
\hline B4 & $\begin{array}{c}\text { Lãnh đạo lắng nghe và tiếp thu ý kiến } \\
\text { đóng góp điêu dưỡng. }\end{array}$ & $\begin{array}{c}154 \\
(59,92 \%)\end{array}$ & 3,62 & 0,69 \\
\hline B5 & $\begin{array}{l}\text { Lãnh đạo động viên, khích lệ điều dưỡng khi } \\
\text { hoàn thành tốt nhiệm vụ, có tiến bộ trong công việc. }\end{array}$ & $\begin{array}{c}153 \\
(59,53 \%)\end{array}$ & 3,63 & 0,66 \\
\hline B6 & $\begin{array}{c}\text { Đồng nghiệp có ý thức hợp tác để hoàn thành nhiệm } \\
\text { vụ chung. }\end{array}$ & $\begin{array}{c}190 \\
(73,93 \%)\end{array}$ & 3,82 & 0,58 \\
\hline B7 & Môi trường làm việc thân thiện, đoàn kết. & $171(66,54 \%)$ & 3,75 & 0,61 \\
\hline B8 & $\begin{array}{c}\text { Đồng nghiệp chia sẻ k } \\
\text { nhau trong }\end{array}$ & $\begin{array}{c}190 \\
(73,93 \%)\end{array}$ & 3,81 & 0,58 \\
\hline B9 & Đồng nghiệp quan tâm, giúp đỡ nhau trong cuộc sống. & $180(70,04 \%)$ & 3,80 & 0,62 \\
\hline Điểm & trung bình hài lòng chung với lãnh đạo trực tiếp, đ & đồng nghiệp & $3,71 \pm C$ & 0,49 \\
\hline $\begin{array}{l}\text { ề Trí k } \\
\text { lày cho } \\
\mathbf{3 . 2} . \\
\text { Bản }\end{array}$ & $\begin{array}{l}\text { viện quí } \mathrm{I} / 2018 \text { và quí } \mathrm{III} / 2018 \\
\text { và cộng sự là } 3,79 \text { điểm [4], ng } \\
\text { y Bệnh viện Đa khoa Trung tâm } \\
\text { ự hài lòng về quy chế nội bộ, }\end{array}$ & ệ tốt giû́ & 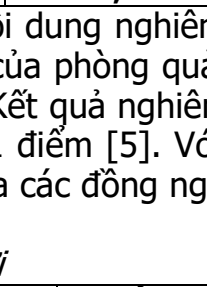 & $\begin{array}{l}\text { kết } \\
\text { ệp. }\end{array}$ \\
\hline $\begin{array}{l}\text { Mã } \\
\text { câu } \\
\text { hỏi }\end{array}$ & Nội dung câu hỏi & $\begin{array}{l}\text { Điêu dưỡng } \\
\text { hài lòng }\end{array}$ & $\begin{array}{l}\text { Điểm } \\
\text { trung } \\
\text { bình }\end{array}$ & $\begin{array}{l}\text { Độ lệ̂̉ch } \\
\text { chuẩn }\end{array}$ \\
\hline C1 & $\begin{array}{l}\text { Các quy định, quy chế làm việc nội bộ của bệnh viện rõ } \\
\text { ràng, thực tế và công khai. }\end{array}$ & $\begin{array}{c}137 \\
(53,31 \%)\end{array}$ & 3,55 & 0,63 \\
\hline C2 & Môi trường làm việc tại khoa/phòng và bệnh viện dân chủ & d. $140(54,47 \%)$ & $\%)$ & 0 \\
\hline $\mathbf{C 3}$ & Quy chế chi tiêu nội bộ cc & $133(51,75 \%)$ & & 0,63 \\
\hline $\mathbf{C 4}$ & Việc phân phối & $130(50,58 \%)$ & 3,51 & 0,64 \\
\hline C5 & Mức lương tương xứng so & $113(43,97 \%)$ & 3,32 & 0,78 \\
\hline C6 & Chế độ phụ cấp nghề và độc hại xứng đáng so với cống hiến. & 1. $103(40,08 \%)$ & 3,23 & 0,85 \\
\hline
\end{tabular}




\begin{tabular}{|c|c|c|c|c|}
\hline C7 & Thưởng và thu nhập tăng thêm ABC xứng đáng so với cống hiến. & $112(43,58 \%)$ & 3,33 & 0,79 \\
\hline C8 & $\begin{array}{c}\text { Cách phân chia thu nhập tăng thêm công bằng, khuyến } \\
\text { khích nhân viên làm việc tích cực. }\end{array}$ & $\begin{array}{c}113 \\
(43,97 \%)\end{array}$ & 3,36 & 0,74 \\
\hline C9 & $\begin{array}{c}\text { Bảo đảm đóng BHXH, BHYT, khám sức khỏe định kỳ và các } \\
\text { hình thức hố trợ ốm đau, thai sản đây đủ. }\end{array}$ & $\begin{array}{c}151 \\
(58,75 \%)\end{array}$ & 3,63 & 0,73 \\
\hline C10 & Tố chức tham quan, nghỉ dưỡng đâyy đủ & $153(52,53 \%)$ & 3,61 & 0,69 \\
\hline C11 & Có phong trào thể thao, văn nghệ tích cực. & $135(52,53 \%)$ & 3,54 & 0,64 \\
\hline C12 & Công đoàn bệnh viện hoạt động tích cực. & $139(54,09 \%)$ & 3,55 & 0,62 \\
\hline \multicolumn{2}{|c|}{ Điểm trung bình hài lòng chung với quy chế nội bộ, tiền lương, phúc lợi } & $\mathbf{3 , 4 8 \pm 0 , 5 5}$ \\
\hline
\end{tabular}

Điểm trung bình tại bảng 3.7 là 3,48 điếm đạt $69,6 \%$ thấp hơn nghiên cứu của Lê Trí Khải và cộng sự là 3,55 điểm [4], khảo sát tại Bệnh viện đa khoa Trung tâm Tiền Giang năm 2018 và 2019 lần lượt là 3,80 -3,81 điểm [2][3]. Kết quả nghiên cứu của chúng tôi cao hơn kết quả nghiên cứu của Lê Thanh Nhuận là 3,24 điểm và nghiên cứu của Vũ Xuân Phú là 2,82 điểm [5]. Kết quả đạt được như trên là do quy chế làm việc nội bộ của Bệnh viện đã được cải thiện, rõ ràng, quy chế chi tiêu nội bộ hợp lý, công khai, bảo đảm đóng BHXH, BHYT khám sức khỏe định kỳ đầy đủ, tổ chức tham quan, phong trào thể dục thể thao, văn nghệ tích cực cho NVYT.

3.2.4. Sự hài lòng về công việc, cơ hội học tập và thăng tiến

Bảng 3.8. Điểm trung bình hài lòng vớicông việc, cơ hội học tập và thăng tiến

\begin{tabular}{|c|c|c|c|c|}
\hline $\begin{array}{l}\text { Mã } \\
\text { câu } \\
\text { hỏi }\end{array}$ & Nội dung câu hỏi & $\begin{array}{l}\text { Điêuu dưỡng } \\
\text { hài lòng }\end{array}$ & $\begin{array}{l}\text { Điểm } \\
\text { trung } \\
\text { bình }\end{array}$ & $\begin{array}{c}\text { Độ } \\
\text { lệch } \\
\text { chuẩn }\end{array}$ \\
\hline D1 & Khối lượng công việc được giao phù hợp. & $125(48,64 \%)$ & 3,42 & 0,69 \\
\hline D2 & Công việc chuyên môn đáp ứng nguyện vọng bản thân. & $137(53,31 \%)$ & 3,54 & 0,64 \\
\hline D3 & $\begin{array}{c}\text { Bệnh viện tạo điều kiện cho điều dưỡng nâng cao } \\
\text { trình độ chuyên môn. }\end{array}$ & $167(6$ & 3,71 & 0,64 \\
\hline D4 & $\begin{array}{l}\text { Bệnh viện tạo điêu kiện cho điêuu dưỡng học tiếp } \\
\text { các bậ́c cao hơn. }\end{array}$ & $\begin{array}{c}149 \\
(57,98 \%)\end{array}$ & 3,57 & 0,67 \\
\hline D5 & Công khai các tiêu chuấn cho các chức danh lãnh đạo. & $141(54,86 \%)$ & 3,54 & 0,67 \\
\hline D6 & Bố nhiệm các chức danh lãnh đạo dân chủ, công bằng. & $144(56,03 \%)$ & 3,58 & 0,65 \\
\hline D7 & Có cơ hội thăng tiến khi nồ lực làm việc. & $128(49,81 \%)$ & 3,47 & 0,67 \\
\hline \multicolumn{3}{|c|}{ Điểm trung bìnhhài lòng chung với công việc, cơ hội học } & \multicolumn{2}{|l|}{$3,55=$} \\
\hline
\end{tabular}

Kết quả nghiên cứu của chúng tôi so với nghiên cứu của Vũ Xuân Phú về điểm trung bình hài lòng của NVYT về thăng tiến, bổ nhiệm vị trí lãnh đạo là 2,94 điểm, về học tập nâng cao trình độ chuyên môn là 3,13 điểm [5] thì cao hơn lần lượt là thăng tiến, bổ nhiệm vị trí lãnh đạo là 3,54 điểm, về học tập nâng cao trình độ chuyên môn là 3,57 điểm.

3.3. Một số yếu tố ảnh hưởng đến sự hài lòng của điêuu dưỡng khi làm việc tại Bệnh viện Đa khoa Trung tâm Tiền Giang. Qua phỏng vấn sâu một số điều dưỡng, chúng tôi nhận thấy: Sự hài lò̀ng đối với công việc của điều dưỡng là một yếu tố hết sức quan trọng trong công tác chăm sóc và bảo vệ sức khỏe nhân dân, góp phần nâng cao chất lượng khám chữa bệnh và đáp ứng sự hài lòng cho người bệnh. Muốn vậy, cần phải cải thiện môi trường làm việc, giảm thiểu áp lực công việc, cải tiến công tác quản lý, lãnh đạo và quan hệ đồng nghiệp cũng như quy chế nội bộ, tiền lương, phúc lợi và tạo cơ hội học tập, thăng tiến cho điêu dưỡng...

\section{KẾT LUẬN}

Sự hài lòng với công việc của điêuu dưỡng tại Bệnh viện Đa khoa Trung tâm Tiền Giang: Điểm trung bình và tỷ lệ hài lòng:

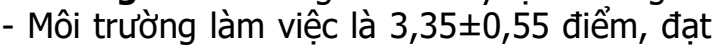
tỷ lệ $67 \%$.

- Lãnh đạo trực tiếp, đồng nghiệp là $3,71 \pm 0,49$ điểm, đạt tỷ lệ $74,2 \%$.

- Quy chế nội bộ, tiền lương, phúc lợi là $3,48 \pm 0,55$ điểm, đạt tỷ lệ 69,6\%.

- Công việc, cơ hội học tập và thăng tiến là $3,55 \pm 0,54$ điểm, đạt tỷ lệ $71 \%$.

Một số yếu tố ảnh hưởng đến sự hài lòng của điều dưỡng

- Tiền lương còn thấp so với năng lực cống hiến của người điều dưỡng.

- Một số ít khoa phòng lãnh đạo còn thiếu quan tầm đến nhân viên y tế.

- Sự quá tải về người bệnh, trực 3 ca 4 kíp tạo áp lực cho điều dưỡng.

\section{KHUYẾN NGH!}


- Đối với lãnh đạo Bệnh viện cần quan tâm và đối xử bình đẳng với điều dưỡng, tạo nguồn kinh phí chi trả tiền lương và phụ cấp tương xứng với cống hiến của điều dưỡng do bệnh viện tự chi hoàn toàn và phân công công việc phù hợp với vị trí làm việc của từng điều dưỡng.

- Đối với đội ngũ điều dưỡng cần rèn luyện, trau dồi, học tập nâng cao trình độ chuyên mổn, nghiệp vụ, cập nhật kiến thức mới và thực hành tốt y đức.

\section{TÀI LIẸU THAM KHẢO}

1. Alan Tiến (2018), "Thang đo Likert và các bước xây dưng Likert hiểu quả".

2. Báo cáo kết quả khảo sát mức độ hài lòng của nhân viên y tế 2018 của Bệnh viện Đa khoa Trung tâm Tiền Giang.
3. Báo cáo tổng kết năm 2019 của Bệnh viện Đa khoa Trung tâm Tiền Giang.

4. Lê Trí Khải (2016), "Sứ hài lòng đối với công viêc của nhân viên y tế cơ sở tỉnh Kon Tum năm 2016".

5. Vũ Xuân Phú (2012), "Thực trạng nguồn nhân lực và một số yếu tố ảnh hưởng đển sự hài lòng với công việc của nhân viên y tế Bệnh viện đa khoa Sóc Sớn, Hà Nôi năm 2011", Tạp chí Ỳ hoc thực hành, 821-5/2012, pp. tr 153-159.

6. Lế Nguyến Đoan Khôi và Đố Hữu Nghi "Các nhân tố ảnh hưởng đến mức độ hài lòng công việc của nhân viên y tế tại Thành Phố Cần thơ năm 2014".

7. Cambridge Dictionary Online (2015), "Cambridge Dictionary Online (2015), job satisfaction. Available from 10/11/2015".

8. Oxford University Press (2015), "Oxford University Press (2015), Principles of Organizational Behaviour 4e: Glossary. Available from .htm, accessed 12/02/2017".

\section{TÌM HIỂU MộT SỐ ĐĂC ĐIỂM LÂM SÀNG, X-QUANG, CẮT LỚP VI TÍNH CỦA BỆNH NHÂN GÃY KÍN DUPUYTREN ĐƯợC KẾT XƯƠNG BÊN TRONG TẠI BỆNH VIỆN TRUNG ƯƠNG QUÂN ĐộI 108}

\section{TÓM TẮT}

Muc tiêu: Gãy Dupuytren là môt tổn thương đăc biệt vừng cổ chân, là một tổn thương thường gặp trển lâm sàng. Mục tiêu của nghiên cứu này là tìm hiểu đăc điểm lâm sàng, XQ, CT Scanner của loại gãy này. Đối tượng, phương pháp: Đối tượng nghiên cứu gồm 38 BN gãy kín Dupuytren, được phâu thuật kết xương bên trong từ 9/2015-6/2020 tại Bênh viện TWQĐ 108. Có 22 nam và 16 nữ, tuổi trung bình 46,26 tuổi (2272), trong đó gãy ở chân trái là $23 \mathrm{BN}$, gãy chân phải là 15 BN. Nguyên nhân tổn thương là TNGT gặp ở 20 $\mathrm{BN}$, do TNLĐ gặp ở $2 \mathrm{BN}$, do ngã gặp ở $13 \mathrm{BN}$, do TNTT gặp ở 3 BN. Các BN được chụp XQ thẳng, nghiêng. Chụp CT Scanner được thực hiện ở 20 BN gãy 3 mắt cá. Các đăc điểm lâm sàng, XQ, CT Scanner được thu thập và phân tích. Kết quả: 20 BN gãy 3 mắt cá, 17 BN gãy 2 mắt cá, $1 \mathrm{BN}$ gãy mắt cá ngoài đơn thuần. Có 2 BN gãy loại I, 8 BN gãy loại II, 4 BN gãy loại III, 2 BN gãy loai IV theo phân loại gãy mắt cá sau của Bartonicek. Có 23 BN gãy kiểu Weber B và 13 BN kiểu Weber $C$. Tất cả BN đều có hình ảnh tổn thương mộng chày mác và bán trật xương sên ra ngoài. Cơ chế tổn thương chính là xoay ngoài (33/38 BN). Chẩn đoán gãy mắt cá sau dựa vào đường gãy chéo vát trên phim $X Q$ tư thế nghiêng của $20 \mathrm{BN}$ và hình ảnh đường viền kép ở $4 \mathrm{BN}$ và hình núi mờ ở 16 $\mathrm{BN}$ trên phim $\mathrm{X}$ quang thẳng. $\mathrm{CT}$ Scan cho thấy kích

${ }^{1}$ Bệnh viện TUQQĐ 108

Chịu trách nhiệm chính: Nguyễn Văn Lượng

Email: luongnv@gmail.com

Ngày nhận bài: 8/8/2021

Ngày phản biên khoa hoc: 10/9/2021

Ngày duyệt bài: 30/9/2021
Nguyễn Văn Lượng ${ }^{1}$, Nguyễn Điện Thành Hiệp ${ }^{1}$

thước, vị trí gãy, hình ảnh lún, chèn mảnh gãy nhỏ, di lệch lớn của mảnh gãy mắt cá sau ngay trên diện khớp. Kết luân: Gãy Dupuytren với các tổn thương đặc trưng: Gãy mắt cá ngoài, gãy mắt cá trong hoặc đứt dây chằng Delta; doãng mộng chày mác, có hoặc không có kèm gãy mắt cá sau. Cơ chế tổn thương chủ yếu là xoay ngoài cổ chân. XQ có thể chẩn đoán được gãy Dupuytren, tuy nhiên XQ có một số hạn chế trong chẩn đoán tổn thương gãy mắt cá sau, vì vậy nên chụp CT Scans để đánh giá gãy mắt cá sau. mắt cá

Tư khóa: Gãy Dupuytren, gãy 2 mắt cá, gãy 3

\section{SUMMARY \\ RESEARCH FEATURES OF CLINICAL SIGNS RADIOGRAPH AND COMPUTED TOMOGRAPHY (CT) SCANS OF PATIENTS WITH CLOSED DUPUYTREN FRACTURE TREATED WITH OPEN REDUCTION AND INTERNAL FIXATION IN 108 CENTRAL MILITARY HOSPITAL}

Objective: Dupuytren fracture is a special type of ankle's injury which are popular in clinic. The aim of this study is to investigate the clinical features and radiograph features and computed tomography (CT) scans of these fracture. Patients and methods: The data of 38 patients with closed Dupuytren fracture from September 2015 to June 2020, who were treated with open reduction and internal fixation in 108 Central Military Hospital were retrospectively analyzed. There were 22 males and 16 females, the average age was 46.26 years (range, 22 to 72 years), the fractures occurred on the left side in 23 patients and on the right side in 15 patients. The cause of injuries were traffic accidents in 20 patients, labor accident in 2 